\title{
High flux commercial illumination solution with intelligent controls
}

Final Report

Report Period Start Date:

Report Period End Date:

Principal Investigator:

DOE Award Number:
April 1, 2010

March 31, 2012

Camil Ghiu

DE-EE0003241

Acknowledgment:

This material is based upon work supported by the Department of Energy under Award Number DE-EE0003241. 


\section{Disclaimer:}

This report was prepared as an account of work sponsored by an agency of the United States Government. Neither the United States Government nor any agency thereof, nor any of their employees, makes any warranty, express or implied, or assumes any legal liability or responsibility for the accuracy, completeness, or usefulness of any information, apparatus, product, or process disclosed, or represents that its use would not infringe privately owned rights. Reference herein to any specific commercial product, process, or service by trade name, trademark, manufacturer, or otherwise does not necessarily constitute or imply its endorsement, recommendation, or favoring by the United States Government or any agency thereof. The views and opinions of authors expressed herein do not necessarily state or reflect those of the United States Government or any agency thereof. 


\section{TABLE OF CONTENTS}

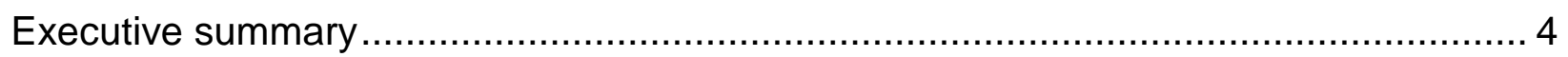

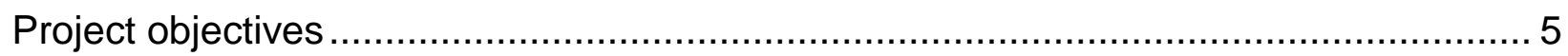

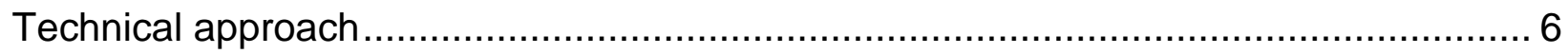

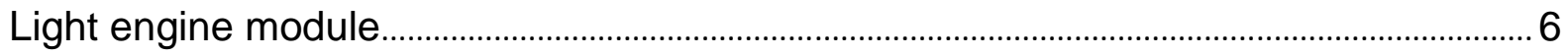

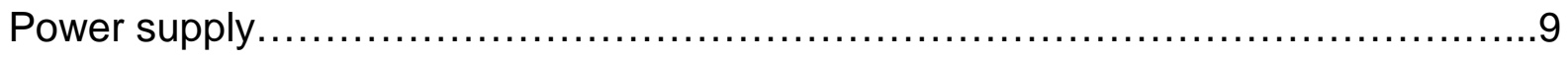

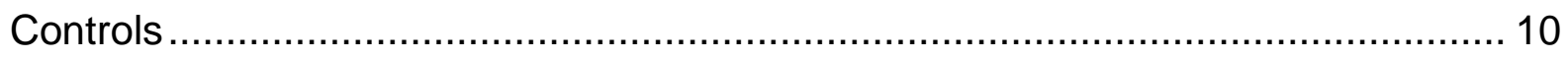

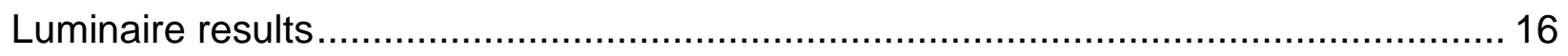

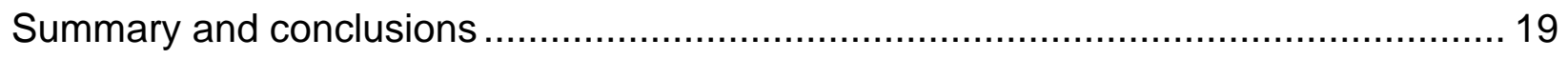

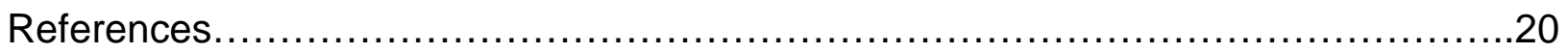




\section{EXECUTIVE SUMMARY}

This report summarizes the work performed at OSRAM SYLVANIA under US Department of Energy contract DE-EE0003241 for developing a high efficiency LEDbased luminaire. A novel light engine module (two versions: standard and super), power supply and luminaire mechanical parts were designed and tested. At steadystate, the luminaire luminous flux is 3156 lumens $(\mathrm{Im})$, luminous efficacy $97.4 \mathrm{LPW}$ and $\mathrm{CRI}(\mathrm{Ra}) 88$ at a correlated color temperature (CCT) of $3507 \mathrm{~K}$. When the luminaire is fitted with the super version of the light engine the efficacy reaches $130 \mathrm{LPW}$. In addition, the luminaire is provided with an intelligent control network capable of additional energy savings. The technology developed during the course of this project has been incorporated into a family of products. Recently, the first product in the family has been launched. 


\section{PROJECT OBJECTIVES}

The objective of this work was to design and build an LED based luminaire with the following performance targets:

(1) Luminous flux of $\mathbf{3 0 0 0}$ lumens. Approximate lumens equivalent to 2' x 2' fluorescent parabolic troffer.

(2) 92 lumens per watt steady-state luminaire efficacy. To reach this level of performance, a combination of 130LPW LED source and luminaire efficiency of $76 \%$ was proposed. The luminaire efficiency includes electrical, thermal, and optical losses.

(3) Intelligent control electronics

(4) 100,000 hours system lifetime

(5) Excellent color quality. Defined as having a correlated color temperature (CCT) of $3500 \mathrm{~K}$ and a color rendering index $\left(R_{a}\right)$ of $\geq 85$.

Table 1 presents the proposed performance metrics for the luminaire against the DOE goals for 2012 and 2015 as defined in the MYPP ${ }^{1}$ at the time of the proposal (2009):

Table 1. Luminaire proposed performance.

\begin{tabular}{|l|c|c|c|}
\hline \multicolumn{1}{|c|}{ Metric } & $\begin{array}{c}\text { Proposed LED } \\
\text { luminaire ( 2012 ) }\end{array}$ & $\begin{array}{c}\text { DOE } \\
\mathbf{2 0 1 2}\end{array}$ & $\begin{array}{c}\text { DOE } \\
\mathbf{2 0 1 5}\end{array}$ \\
\hline Warm white LED efficacy (Im/W, 25C) & 114 & 141 & 202 \\
\hline Thermal efficiency & $95 \%$ & $86 \%$ & $88 \%$ \\
\hline Driver efficiency & $92 \%$ & $86 \%$ & $89 \%$ \\
\hline Luminaire (optical) efficiency & $92 \%$ & $86 \%$ & $89 \%$ \\
\hline Resultant luminaire efficiency & $80 \%$ & $64 \%$ & $69 \%$ \\
\hline Resultant warm white luminaire efficacy (Im/W) & 92 & 74 & 123 \\
\hline
\end{tabular}




\section{TECHNICAL APPROACH}

\section{LIGHT ENGINE MODULE}

The design of the light engine module was driven primarily by the efficacy and color rendering requirements. In order to deliver at least 92 LPW at steady state at the luminaire level, we need to base our system on a very efficacious light engine. OSRAM's Brilliant Mix ${ }^{2}$ approach of combining phosphor converted InGaN greenish white (called EQ white) and InGaAIP amber LEDs was chosen for its combination of high efficacy and excellent color rendering (Figure 1). In addition, the light engine must deliver good light uniformity and color quality. An optimized light engine layout featuring a unique arrangement of LED chips was created in order to deliver smooth, uniform light.
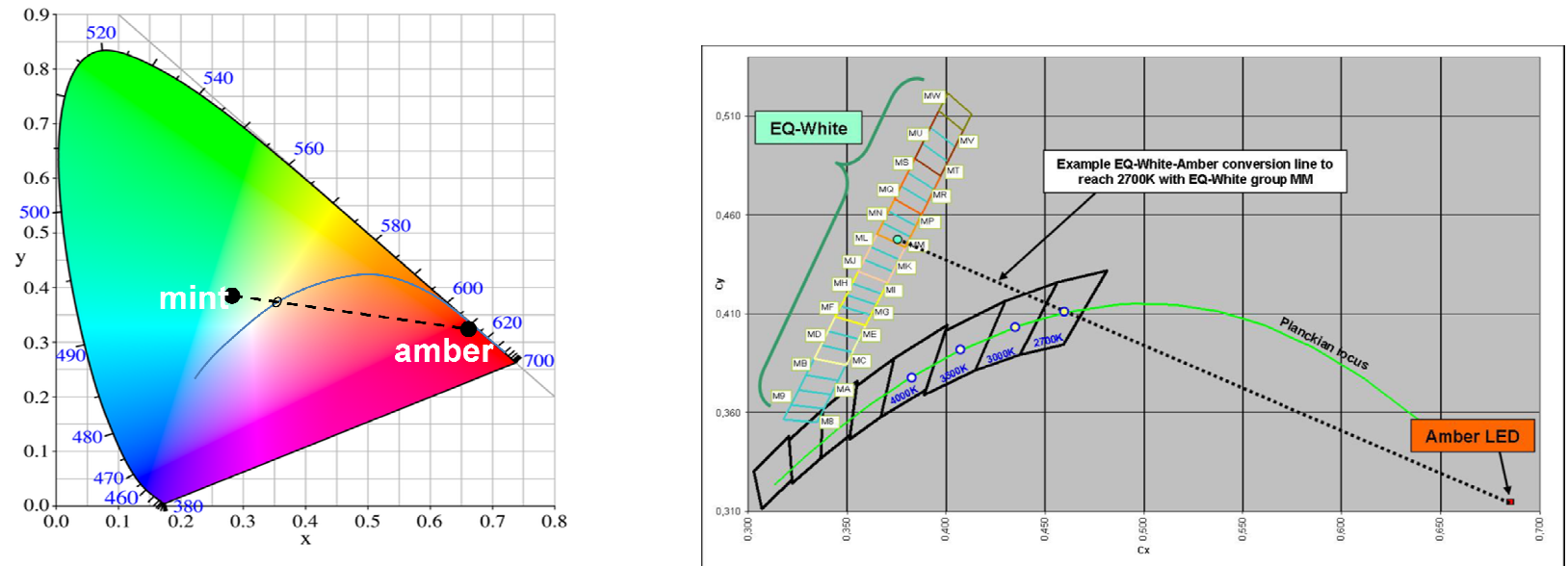

Figure 1. The Brilliant Mix: concept and implementation. 


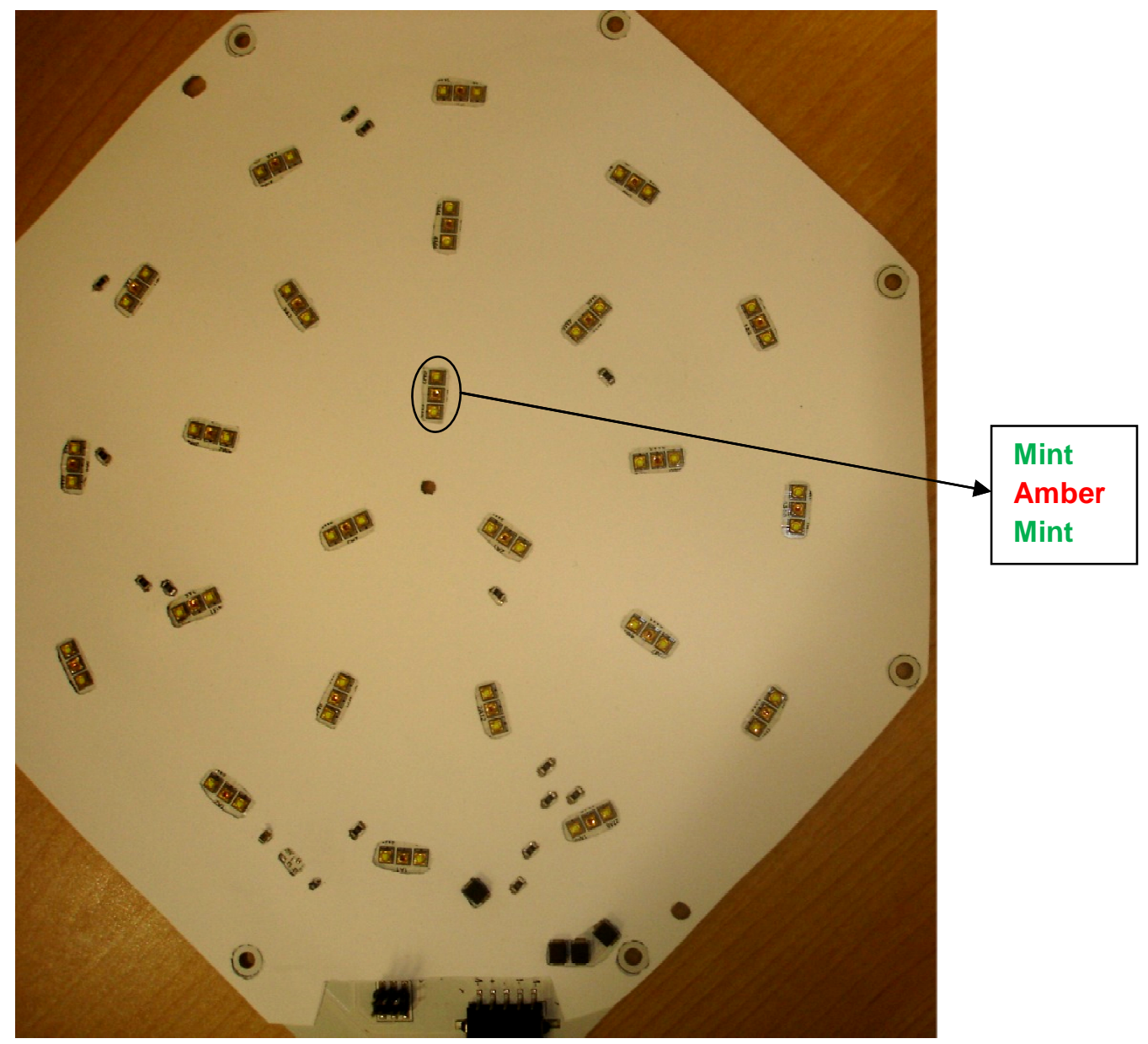

Figure 2. Light engine board (standard version).

The layout for the light engine is based on an existing design, adapted for the needs of this project. The light engine was built in two versions: a standard version with 72 LEDs (48 Oslon mint phosphor converted InGaN LEDs, 24 Oslon® InGaAIP amber LEDs) and a super version with 121 LED (81 Oslon $\AA$ mints, 40 Oslon $\AA$ ambers). As shown in Figure 2, the standard version features 24 groups of 3 LEDs (two mints, one amber) for good color mixing. The light engine was assembled into a mixing chamber formed by a heat sink, a reflector board cover, a reflector cone and a diffuser. The reflector cover is made by White Optics with $98 \%$ reflectance and the cone is made of Furukawa film with $99 \%$ reflectance. The diffuser is a Plaskolite acrylic sheet with white additive. It has just enough diffusivity to hide the light source. Together, these components provide a uniformly illuminated area and good lumen output. Figure 3 below shows an unlit and a lit view of the mixing chamber.

Several light engine modules were tested at steady state. A luminous efficacy of 117 LPW (156 LPW for the super version) was obtained (electrical losses not included). The CCT was $3500 \mathrm{~K}$ and the CRI 88. 


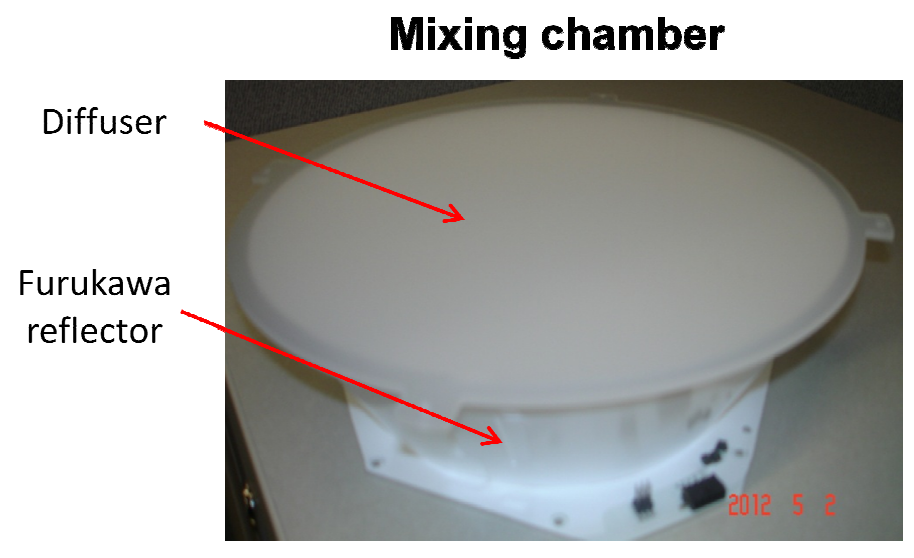

\section{Lit light engine module}

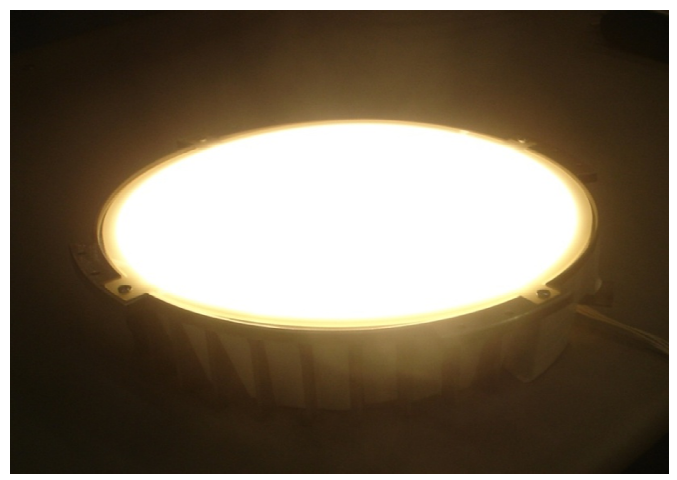

Figure 3. Mixing chamber (unlit and lit).

LEDs experience color shift as the junction temperature changes. Different types of LEDs, such as InGaN and InGaAIP, have different photometric characteristics and deviate from the nominal in different rates against temperature. However, it is possible to minimize the color shift by intelligently controlling the lumen ratio between mints and ambers. To achieve this, the light engine incorporates two feedback control loops. Figure 4 below exemplifies the color shift compensation using the thermal feedback loop. The software built in to the color-mix light engine includes algorithms to control dimming and to ensure that the color and brightness remain stable as a function of both temperature (color maintenance) and of age (lumen maintenance).

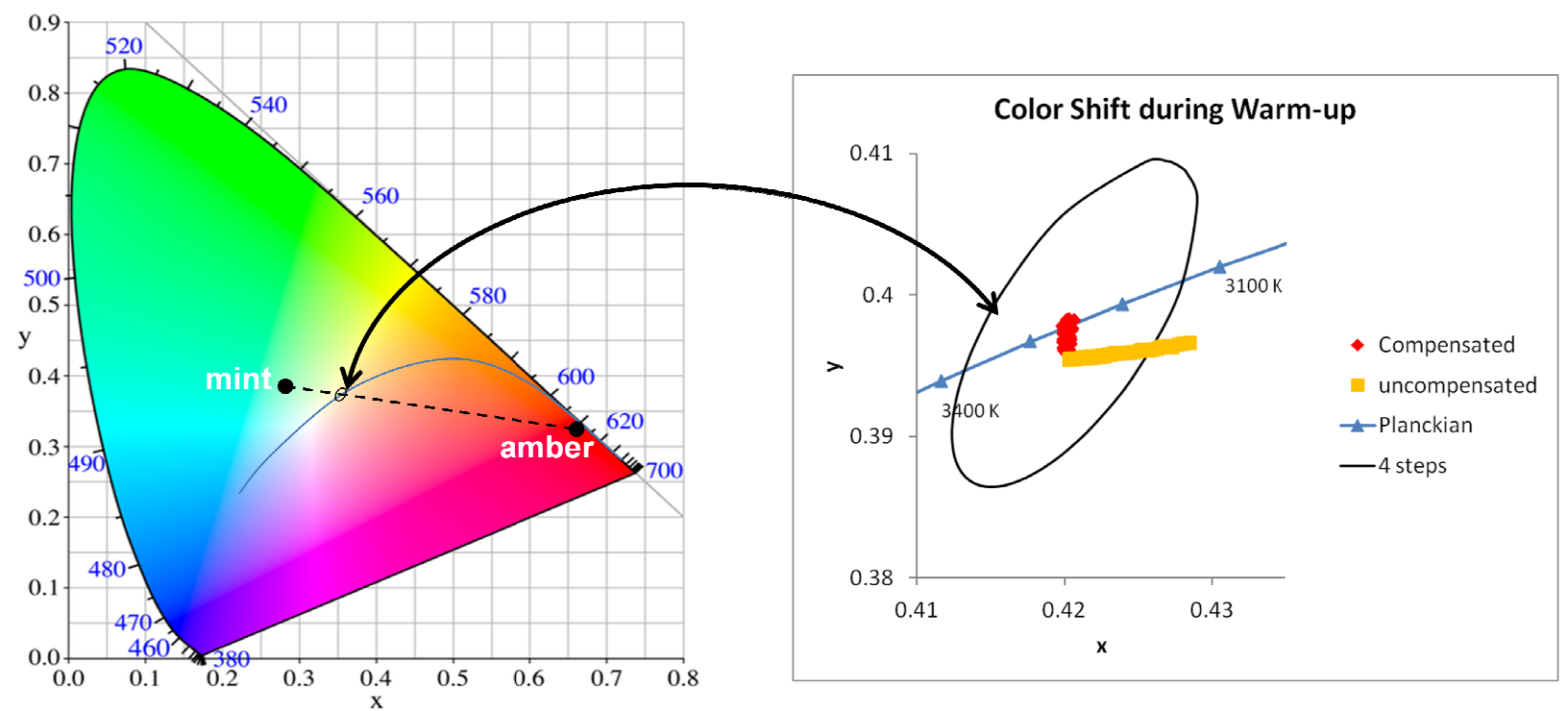

Figure 4. Color shift compensation using thermal feedback. 
Aging (lumen) compensation is based on known depreciation rates for the LEDs and on active monitoring and correction. At regular (but long) intervals, the algorithm measures separately the brightness of the mint and amber LEDs, using an on-board photodiode. Corrections are then made to the lamp operating parameters. Background effects (such as sunlight shining on a red carpet) are subtracted from the signal and do not affect the light. The photodiode algorithm responds only to long term trends measured over a period of months.

The light engine and power supply are calibrated separately so they can be individually replaced in the field. The operator or installer only needs to connect the output to the appropriate resistor. The unit will not miscalibrate itself if an LED load or a noticeably incorrect resistor is connected. The light engine calibration instrument heats the board to normal operating temperature and then measures the temperature of the light engine circuit board, the color and brightness of both mint and amber LEDs, and the response of the photodiode to each color of LEDs. It adjusts the currents provided by the power supply to each light engine channel and writes the pulse width table into the light engine control board memory.

\section{POWER SUPPLY}

The power supply is based on an existing product. This was done in order to shorten the product time to market. The unit selected was OT 50 (Figure 5 below), a 50 W multi-output power supply, part of the OSRAM family of LED power supplies.

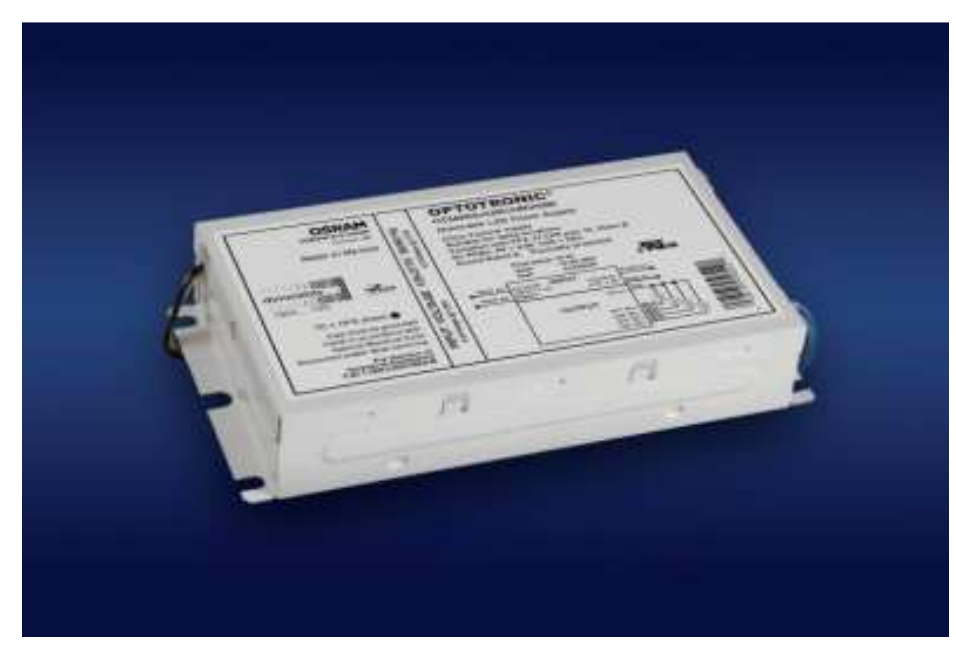

Figure 5. OT 50. 
This unit is a constant current power supply with universal input voltage (120 277 V AC). Four independently controllable output channels (Figure 6 below) with custom output configurations available ensure the necessary flexibility in driving multiple loads at the same time. Each channel has individually addressable pulse width modulation (PWM).

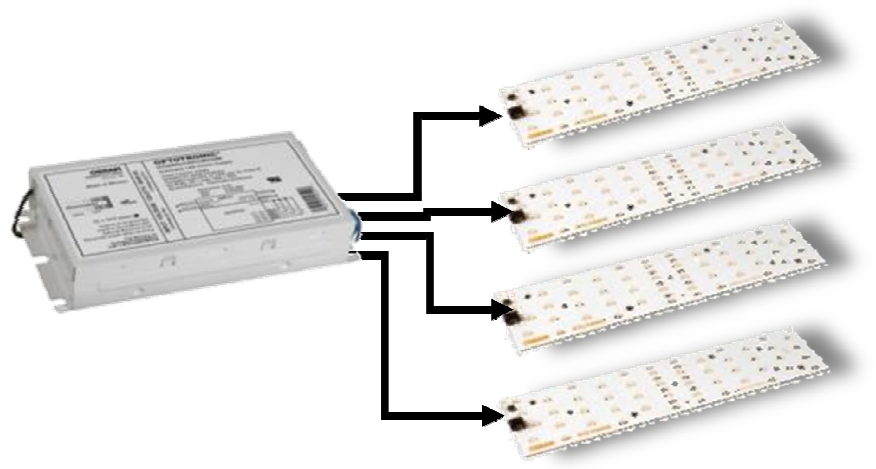

Figure 6. OT 50 with 4 output channels.

The power supply has a peak efficiency of $87 \%$ and a power factor in excess of 0.9. The total harmonic distortion (THD) is less than $20 \%$ and it is dimmable with $0-10$ $\mathrm{V}$ dimmers.

In order to be able to control the color mixing light engine, the power supply's standard control card has been modified by adding a dedicated microprocessor and a communication cable. The embedded intelligence allows for digital communication between the light engine and the power supply.

In parallel with the main development activities, new power supply design methodologies are being investigated with the objective of extending the operating life to 100,000 hours. These novel methodologies include taking into account the components characteristics and operating modes, as well as control techniques. Also, redundant designs including dual components with the shortest expected lifetime (one in function, one in standby) are being considered.

\section{CONTROLS}

The proposal was to design an intelligent self commissioning control system using a multiplicity of networked sensors within the fixtures for redundancy and maximum omniscience. The proposed illuminance control system would leverage available daylight by adding just enough electric light to meet preset total illuminance level for the space. This sensor rich network of fixtures will be designed to provide 
individual light level control for room occupants. The proposed system would also reduce the total installed cost by eliminating much of the labor costs normally associated with reconfiguration and rewiring of control networks by handling many changes through software. Hence, building managers can save time by leveraging the system's flexibility when adapting the space to changing occupant needs. A robust sensor network within fixtures would work together to establish "pools of light". The design would also allow for top tuning (peak shaving) needs and support demand response events. The fixtures will monitor and report power consumption data, energy savings, internal vital signs and log events that may affect money savings and reliability.

\section{Project implementation:}

The first phase of this project focused on simulation of the control scheme using MATLAB/SIMULINK. A 3D model of workspace with scene control was created. Hardware implementation of the control system was the focus of the second phase of this project.

Simulation results:

1. Daylight control model: A SIMULINK model of a closed loop daylight control system was designed to simulate its behavior. This provided critical information regarding stability of the $\mathrm{PI}$ control loop; step and transient response characteristics of the daylight control system (Figure 7).
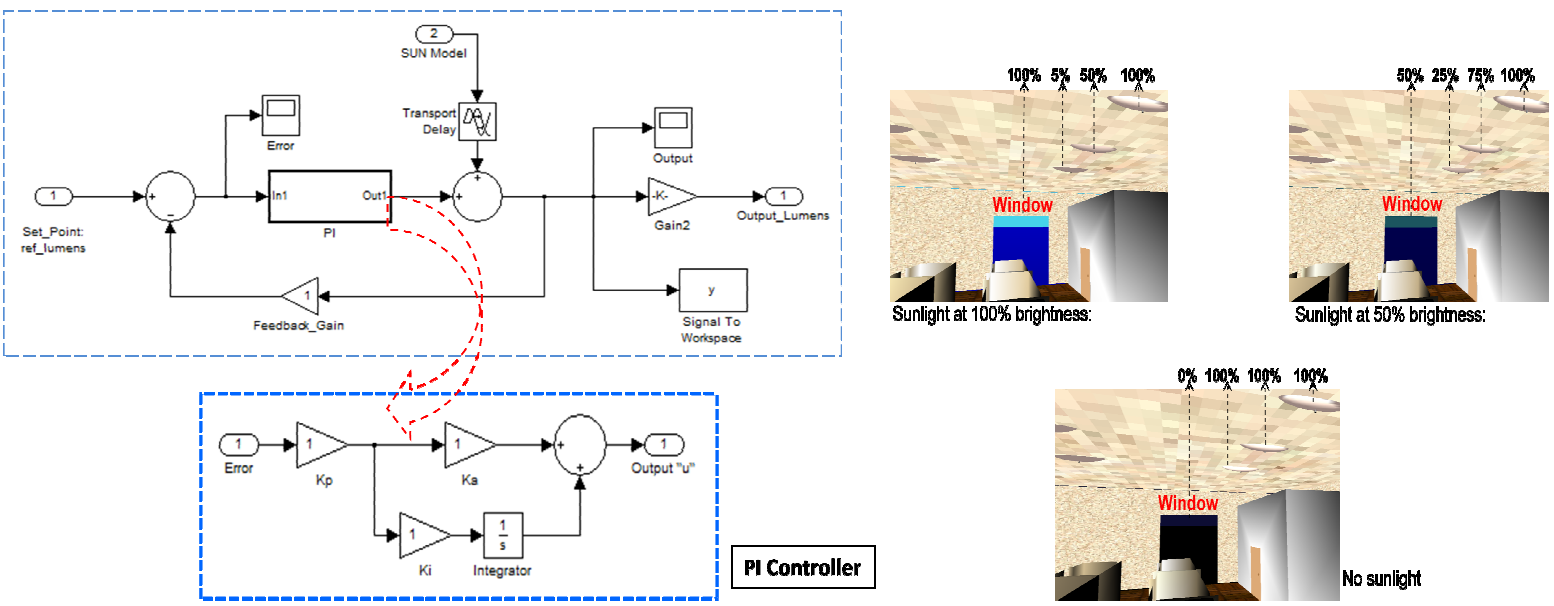

Figure 7. Simulink model of the daylight control system with virtual reality simulation. 
2. Occupancy control model: The objective of this control model was to simulate behavior of multi-zone occupancy sensor control system. Three zones were simulated with a moving occupant (Figure 8).
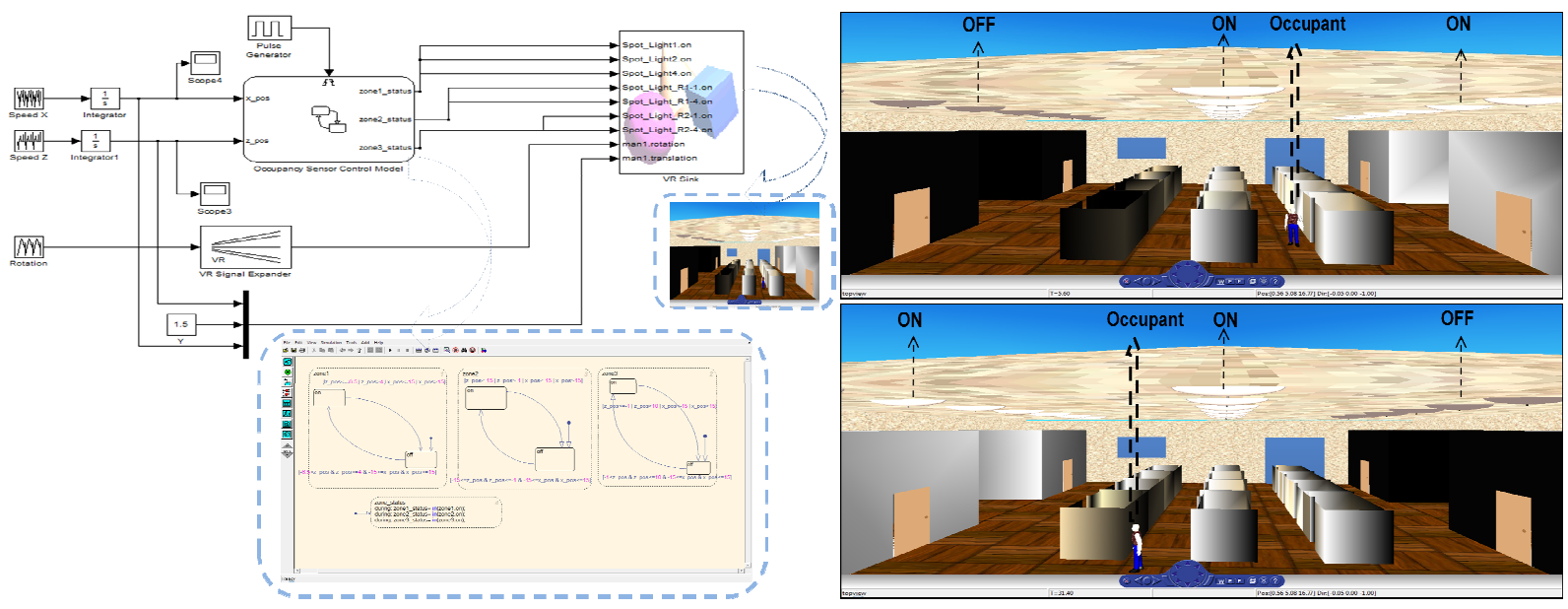

Figure 8. Occupancy control model with virtual reality simulation.

Hardware design:

The controls solution for this project is based on an existing control system, the Encelium Energy Management System, which includes POLARIS 3D software. This section describes the steps taken towards hardware implementation of the control system. It also points out key features of the pilot installation. The overall architecture of control system is presented in Figure 9.

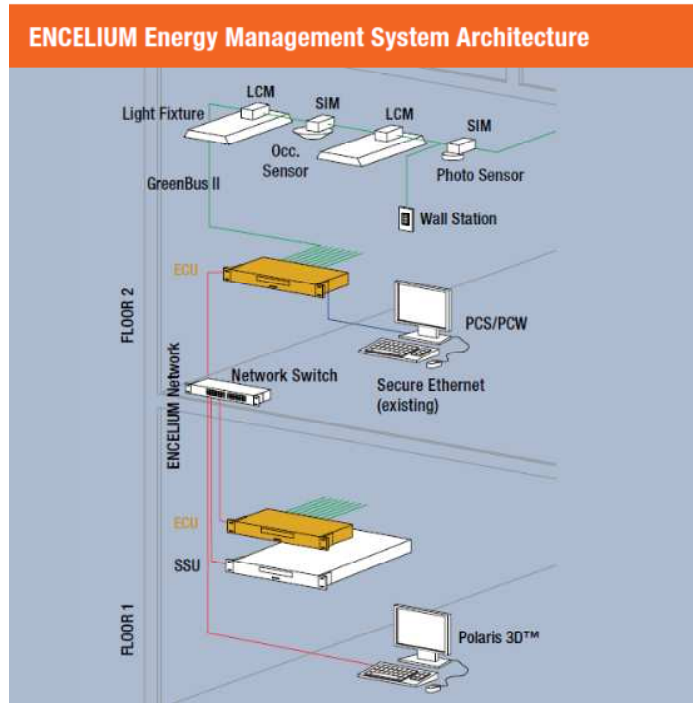

Figure 9. Architecture of Energy Management System. 
Development cycle:

a. A hardware prototype of the occupancy/daylight control system was designed based on the C-code generated from simulation models. OSRAM's LS-PD (Light Sensor-Presence Detection) sensors were used to provide loop feedback.

b. Encelium control system was installed at two locations - Sylvania HQ 2nd floor and R\&D center at $54 \mathrm{CH}$. Initial implementation included only fluorescent fixtures and 500 sqft range occupancy sensors which were daisy chained together to form a nodal network. The luminaires were connected through the Luminaire Control Module (LCM) and the sensors were connected to the Sensor Interface Module (SIM). The central intelligence resides in the Energy Control Unit (ECU) and each node consists of a LCM or a SIM. The following configurations were created using POLARIS software:

i. A CAD layout of the floor plan was created and imported into POLARIS software. The layout is shown in Figure 10.

ii. Zones were created by drawing a box around fixtures or dragging and dropping individual or group of fixtures/sensors into the zones. Then, fixtures/sensors were assigned to respective zones such that a "pool of light" effect is achieved as proposed

iii. Occupancy sensor timeouts were set

iv. Scene settings were added

v. Personal Control Software (PCS) was used to provide individual user control

The above steps clearly illustrated the ease of commissioning the entire system.

c. It was decided to add OSRAM's LS-PD sensors to each fixture to make the network sensor rich and implement a robust and aggressive control strategy. Each sensor is connected to the ECU through the SIM.

d. Next, four 2' x 2' luminaires developed as part of this project were installed in the pilot installation area. Each luminaire is connected to ECU through the LCM. Each new LCM or SIM in configured into the network through POLARIS 3D software.

Here steps 'c' and 'd' illustrate the following:

i. Flexibility in re-configuration

ii. Easy assignment of zones

iii. Sensor and scene control

iv. Ability of the control system to work with both traditional and LED type fixtures. 


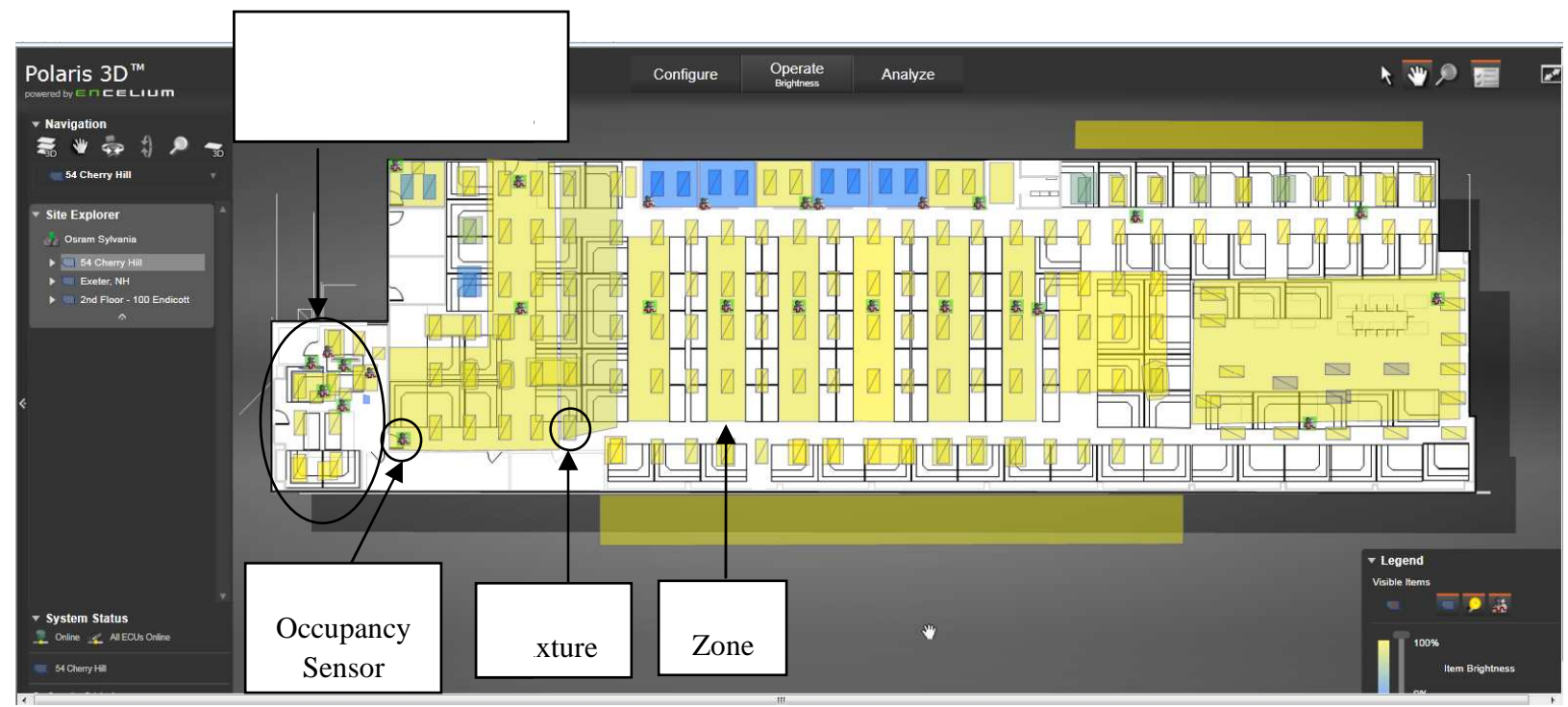

Figure 10. Screen shot of the 54CH floor plan on POLARIS 3D.

The floor plan in Figure 10 shows how groups of fixtures and sensors are tied to different zones. A yellow colored zone means the zone is ON whereas color blue means the zone is OFF. Reconfiguring zones is as easy as drawing a box around fixtures or dragging and dropping individual or groups of fixtures/sensors into a zone.

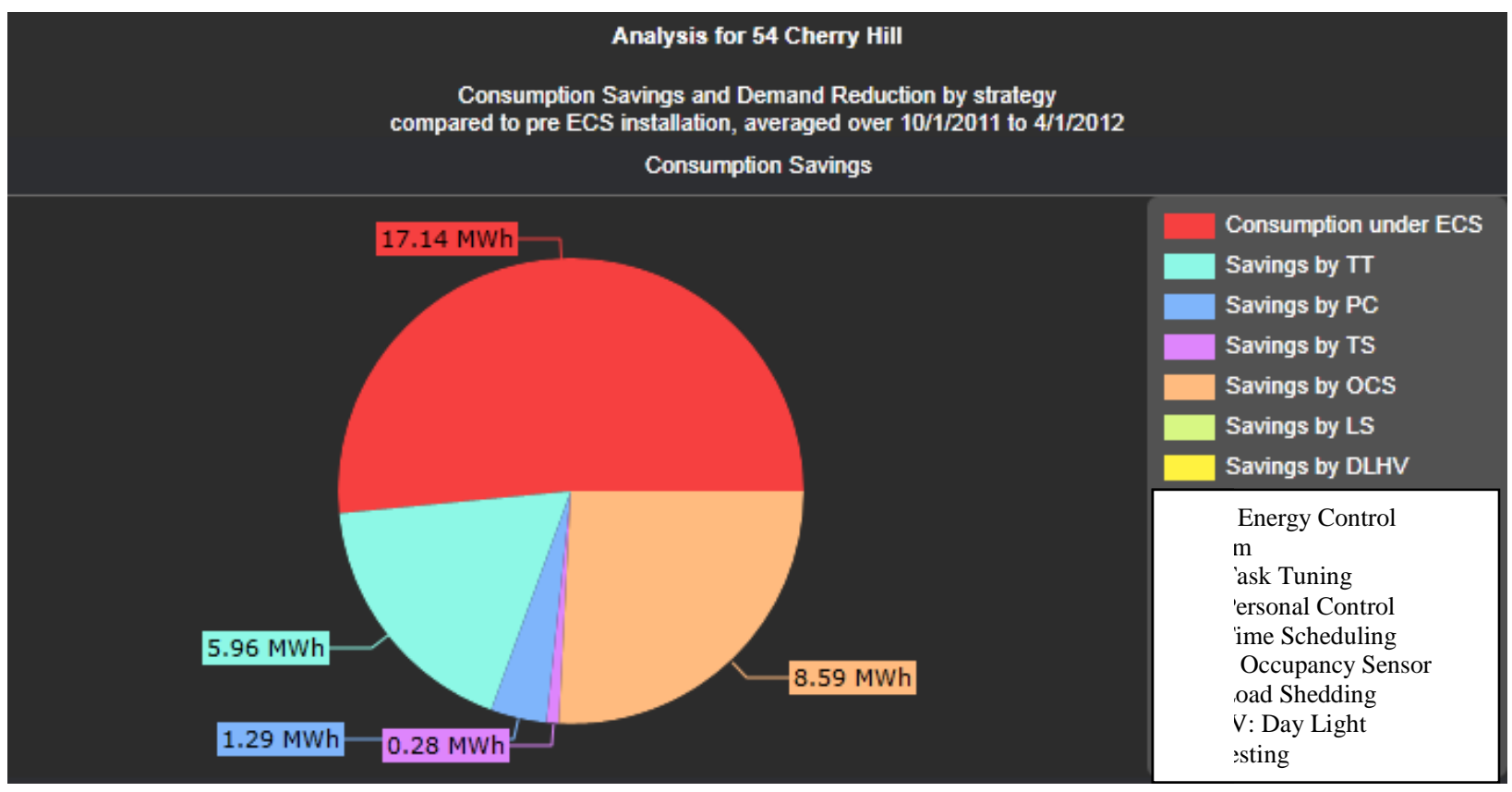

Figure 11. Energy savings report for installation at R \& D center at $54 \mathrm{CH}$. 


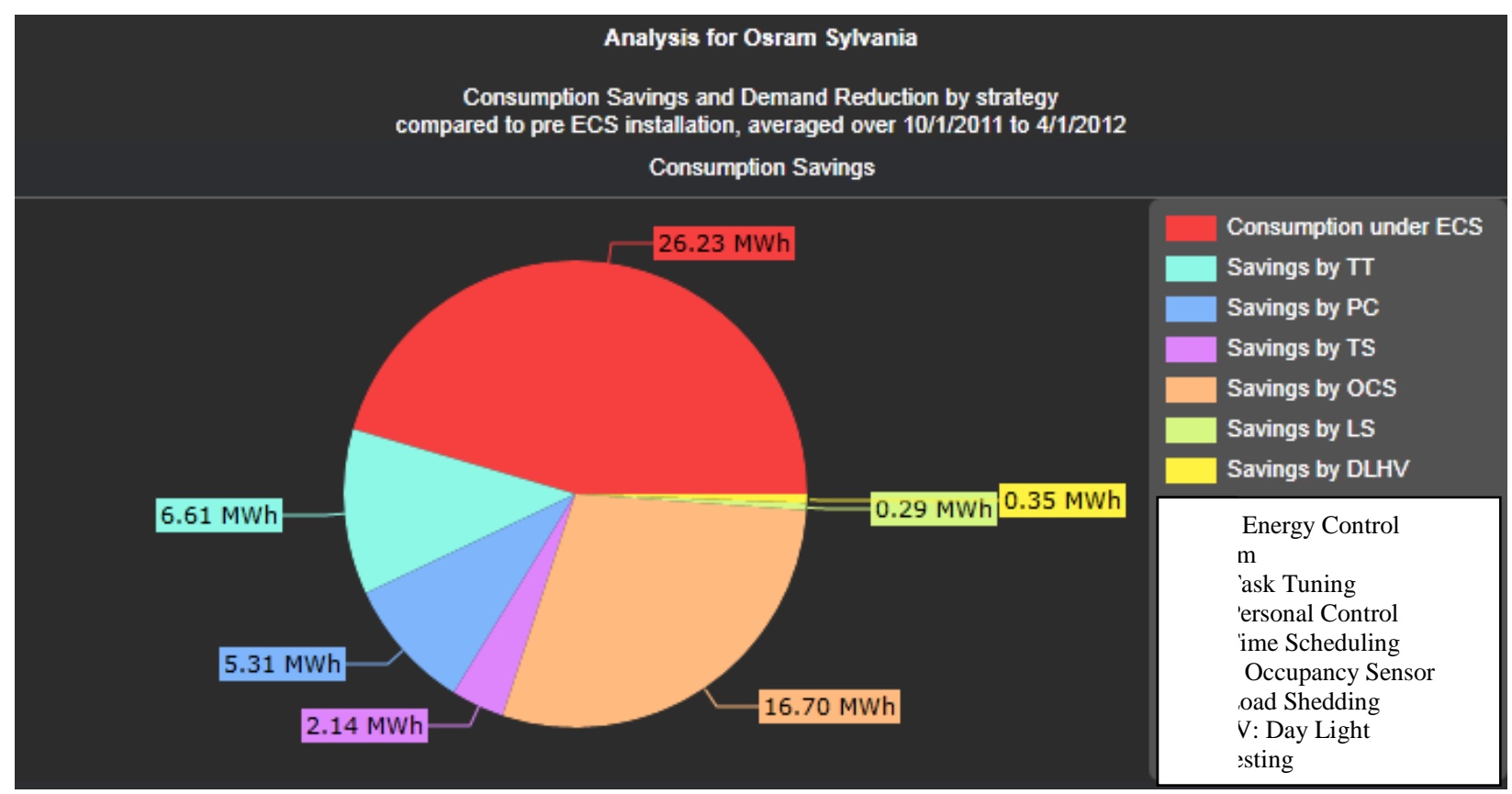

Figure 12. Energy savings report for Sylvania Headquarters.

Figures 11 and 12 illustrate the energy analysis for installations at R\&D centers at 54Ch and Sylvania Headquarters respectively. The analysis is done in POLARIS 3D software. The data is averaged over the 4th quarter of 2011 to 1 st quarter of 2012. Both the figures clearly illustrate the energy consumption and savings by different control strategy (as shown on the right hand column) compared to pre-ECS installation.

Key highlights of pilot installation:

- Flexibility in commissioning and reconfiguration

- Scene control and addressability

- Individual user control assigned to occupants using PLC client

- Ability to get energy savings reports using POLARIS 3D 


\section{LUMINAIRE RESULTS}

Industrial design concepts were incorporated into a novel mechanical design. The goal was to produce an aesthetically pleasing, easy to install luminaire. The exploded view below (Figure 13) details the luminaire mechanical components:

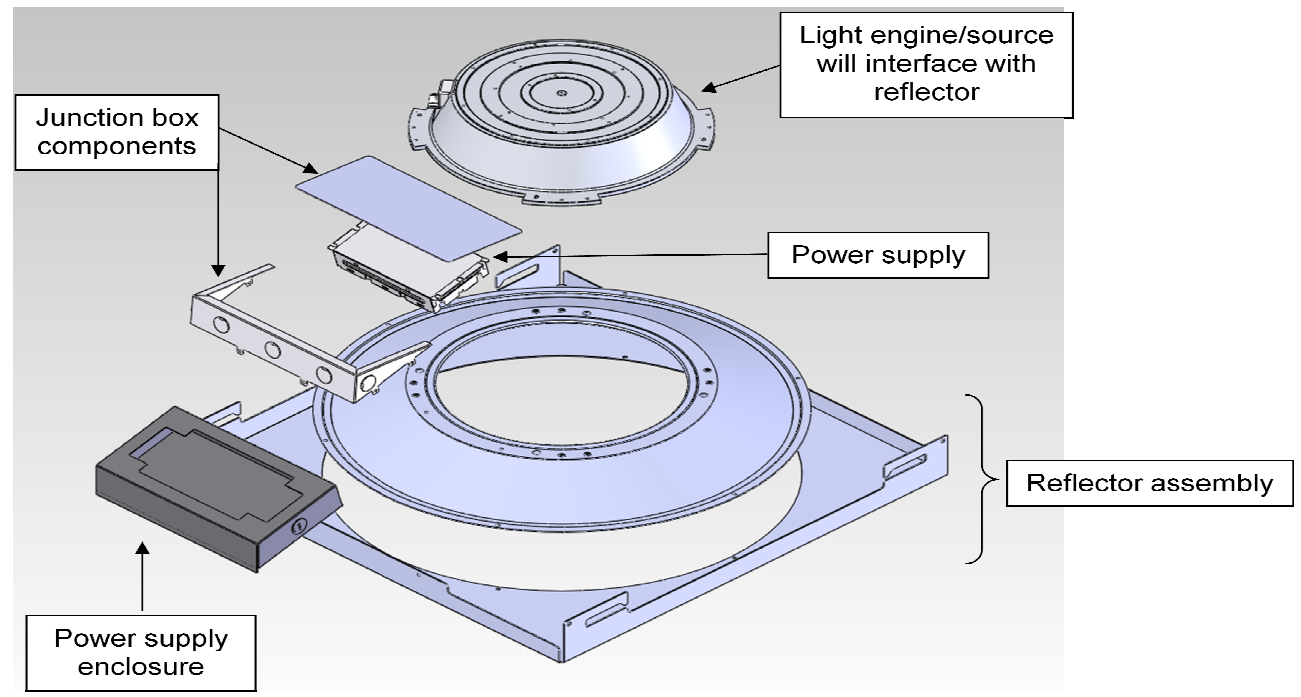

Figure 13. Exploded view of luminaire mechanical components.

Two luminaires in a real office application are shown in Figure 14 below. They are easy to install and exhibit rotational symmetry (for uniform illumination pattern).
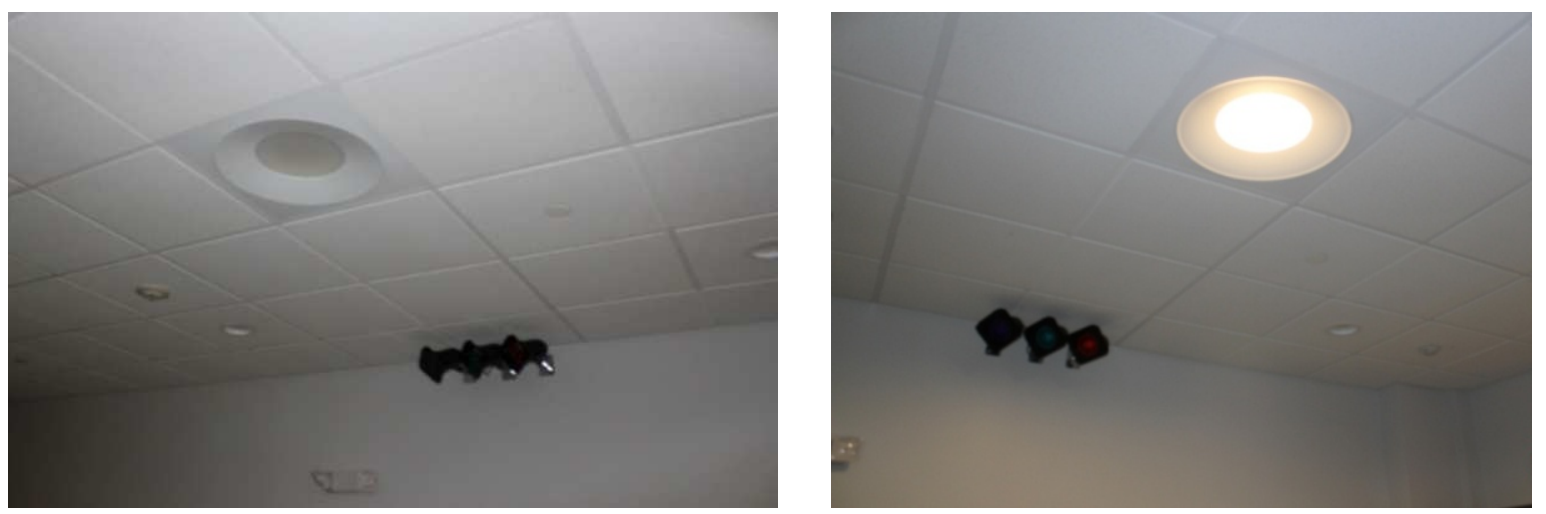

Figure 14. Luminaire installed in the ceiling: unlit (left) and lit (right). 
Photometric measurements were made at steady state using a high speed photogoniometer and a 2.4 meter integrating sphere. The luminaire was operated in its intended orientation in application. Also, the unit was stabilized per the criteria of LM-79 prior to measurement (total operating time prior to measurement was approximately 2 hours). A summary of the results is presented in the Table 2 below. It can be seen that the luminaire exceeded the target values for LPW (97.4) and lumens output (3156) while providing the desired color quality (CCT $3500 \mathrm{~K}$ and CRI 88).

Table 2. Luminaire photometric performance at steady state.

\begin{tabular}{|c|c|c|}
\hline Parameter & Standard version & Super version \\
\hline Input voltage & $120 \mathrm{~V}$ & $120 \mathrm{~V}$ \\
\hline Steady state efficacy & $97.4 \mathrm{LPW}$ & $130 \mathrm{LPW}$ \\
\hline Lumens & 3156 & Up to 4800 \\
\hline CCT & 3507 & 3075 \\
\hline Cx & 0.41 & 0.44 \\
\hline Cy & 0.39 & 0.42 \\
\hline CRI & 88 & 90 \\
\hline
\end{tabular}


Figure 15 illustrates the absolute spectral radiant flux while Figure 16 presents the polar candela distribution.

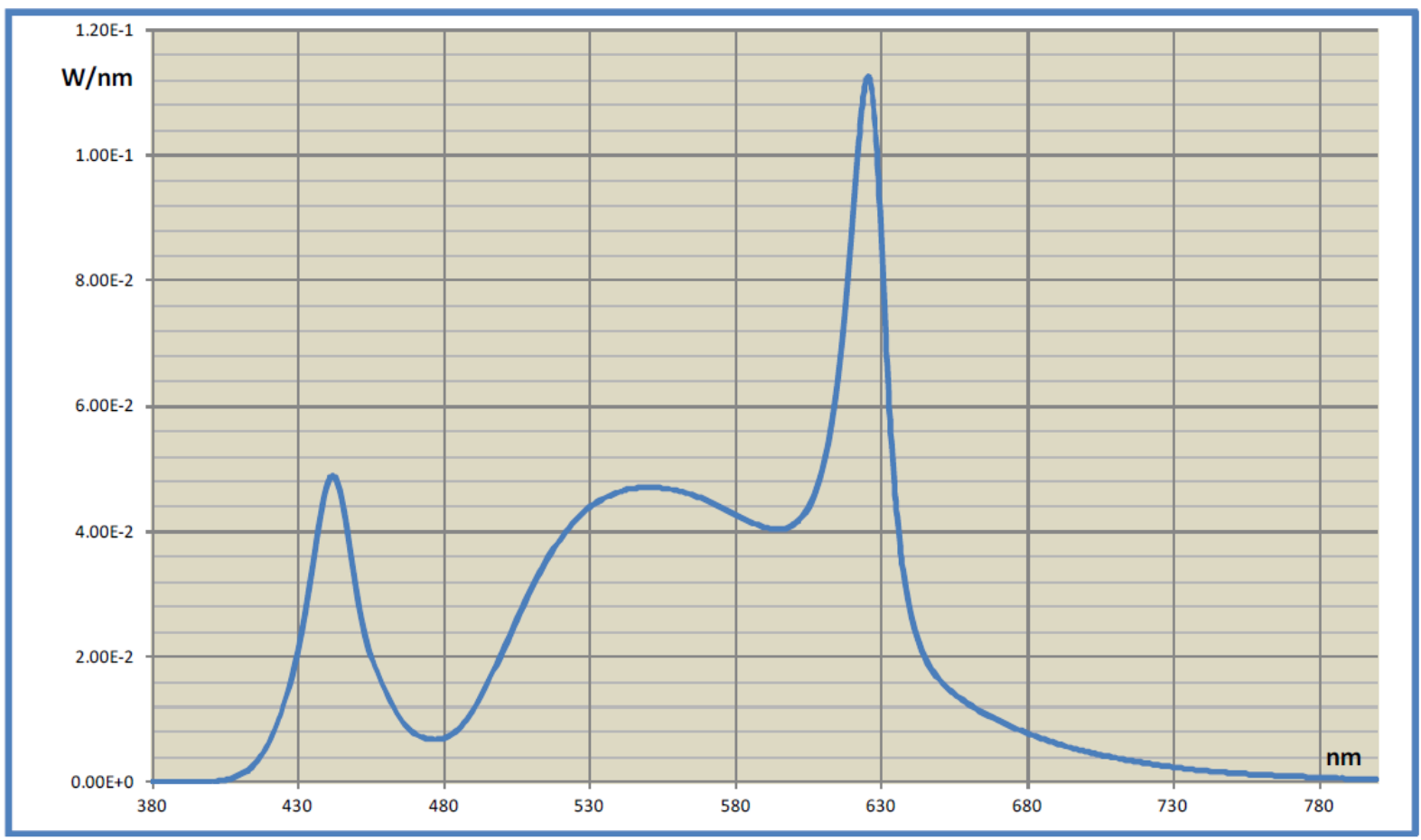

Figure 15. Absolute spectral radiant flux.

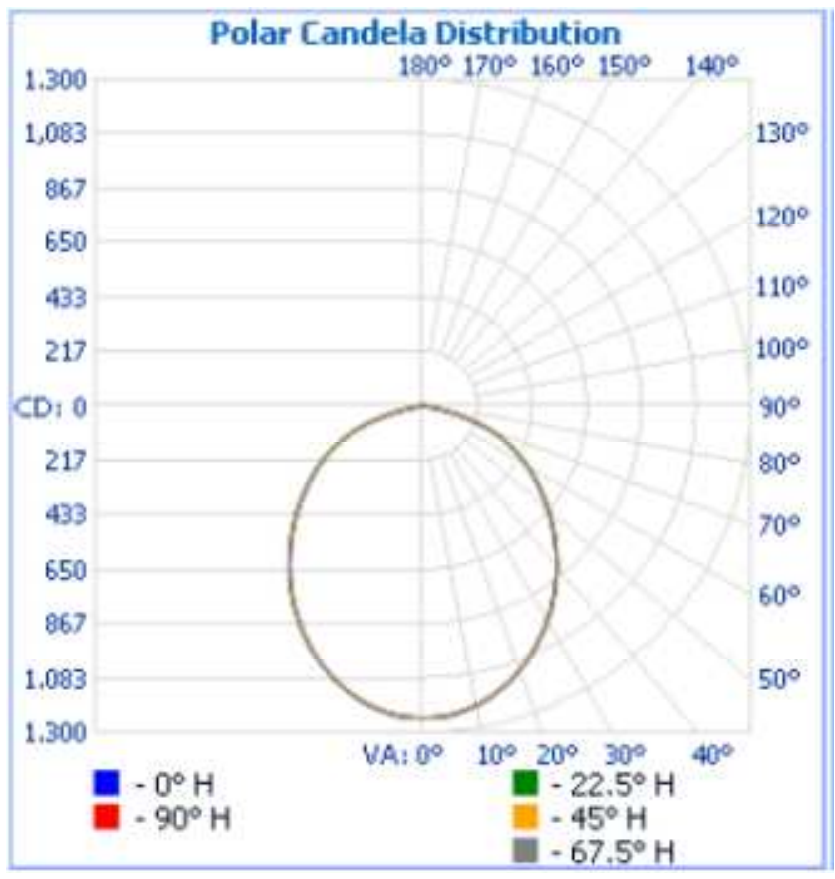

Figure 16. Polar candela distribution. 


\section{SUMMARY AND CONCLUSIONS}

In summary, we designed, built, and tested an efficient 2' $\times 2$ ' LED luminaire delivering $3156 \mathrm{Im}$ at steady state. The luminaire efficacy is $97.4 \mathrm{LPW}$ with the standard light engine and 130LPW with the super light engine. At the core of the luminaire is the light engine module. This module alone achieved 117 (156 for the super version) lumens per watt efficacy at steady state (electrical losses not included). The light engine uses a color mixing approach with selected LEDs resulting in good light uniformity, high optical (95\%) and thermal (96\%) efficiencies.

The module offers good color quality (CCT of $3500 \mathrm{~K}$ and $\mathrm{CRI}$ of 88). Two feedback loops (one thermal, one optical) ensure that the color point stays within two MacAdam steps of the target point during the entire luminaire life and for a wide range of operating temperatures.

The light engine is supplied with constant current by a power supply featuring four independently controllable output channels and superior dimming. The intelligence embedded into the power supply enables digital communication between the power supply and the light engine. In parallel, novel design methodologies to extend the life of the power supply to 100,000 hours are actively being investigated.

The intelligent controls scheme developed as part of this project allows the integration of individual units into an intelligent network of luminaires capable of additional energy savings through occupancy sensing and daylight harvesting.

The technology developed during this project was incorporated into a family of products. Recently, the first product part of the family was launched.

Table 3 below summarizes the results of this project.

Table 3. Project results

\begin{tabular}{|l|c|c|}
\hline \multicolumn{1}{|c|}{ Metric } & $\begin{array}{c}\text { Project } \\
\text { goal }\end{array}$ & $\begin{array}{c}\text { Actual } \\
\text { performance }\end{array}$ \\
\hline Luminous flux & 3000 & $3156(4800)$ \\
\hline Thermal efficiency & $95 \%$ & $96 \%$ \\
\hline Driver efficiency & $92 \%$ & $83 \%$ \\
\hline Luminaire (optical) efficiency & $92 \%$ & $95 \%$ \\
\hline Resultant luminaire efficiency & $80 \%$ & $76 \%$ \\
\hline Resultant warm white luminaire efficacy $(\mathrm{Im} / \mathrm{W})$ & 92 & $97.4(130)$ \\
\hline CCT & 3500 & 3507 \\
\hline CRI & 85 & $88(90)$ \\
\hline
\end{tabular}




\section{References}

${ }^{1}$ Multi-Year Program Plan FY'09-FY'14, Solid-State Lighting Research and Development, Prepared for: Lighting Research and Development, Building Technologies Program, Office of Energy Efficiency and Renewable Energy, U.S. Department of Energy. Prepared by Navigant Consulting, Inc., Radcliffe Advisors, and SSLS, Inc., March 2008.

${ }^{2}$ A. Stich, H. Varga, C. Neugirg, J. Marfeld, F. Michel. Brilliant Mix - Professional White for General Lighting, Application Note, OSRAM Opto Semiconductors, January 2011. 